\title{
archOnline@JCU
}

This is the Accepted Version of a paper published in the journal: Australian Social Work

Gair, Susan, Miles, Debra, Savage, Dorothy, and Zuchowski, Ines (2015) Racism unmasked: the experiences of Aboriginal and Torres Strait Islander students in social work field placements. Australian Social Work, 68 (1). pp. 32-48

http://dx.doi.org/10.1080/0312407X.2014.928335 


\section{RACISM UNMASKED: THE EXPERIENCES OF ABORIGINAL AND TORRES STRAIT ISLANDER STUDENTS IN SOCIAL WORK FIELD PLACEMENT}

\section{Authors:}

Susan Gair ${ }^{a}$, Debra Miles ${ }^{b}$, Dorothy Savage ${ }^{\mathrm{c}}$ and Ines Zuchowski ${ }^{\mathrm{d}}$

a Department of Social Work and Human Services, James Cook University.

b Department of Social Work and Human Services and Deputy Head of the School of Arts and Social Sciences, James Cook University.

c Elder of the Bindal people, the traditional custodians of land on which JCU, Townsville Campus stands, and Indigenous Student Support Officer, James Cook University.

\footnotetext{
${ }^{\mathrm{d}}$ Department of Social Work and Human Services, James Cook University.
} 


\section{Corresponding author:}

\section{Dr. Debra Miles}

Department of Social Work and Human Services,

James Cook University, North Queensland, Australia

Tel: 61747815891

Email: debra.miles@jcu.edu.au 


\begin{abstract}
Attracting more Aboriginal and Torres Strait Islander people to the social work profession is an important strategy in responding to Indigenous disadvantage. The literature suggests that the inclusion of Aboriginal and Torres Strait Islander people, knowledge and skills in social work is impeded by racism and white privilege. This article reports on a research project that aimed to explore the field education experiences of Aboriginal and Torres Strait Islander social work students. Interviews were conducted with 11 Aboriginal and Torres Strait Islander students /graduates and their narratives were analysed through a collaborative process. Findings reveal experiences of subtle and overt racism as every day features of their placements. The findings highlight the need to address racism, the value of cultural mentors, and the necessity to increase the employment of Aboriginal and Torres Strait Islander academic staff in social work education.
\end{abstract}




\section{Introduction}

The subtle dynamics of personal, institutional and cultural racism permeate the routine minutiae of social work policy and practice and these, combined with the strategies white social workers utilise to avoid the tricky task of confronting racism in their work, mean that black people's needs receive short shrift. (Dominelli, 1989, p.1)

It is nearly twenty five years since Dominelli made this observation about racism in the profession of social work. While Dominelli was referring to British social work, Australian authors of the time developed similar arguments (see for example McMahon, 1990). This article discusses recent research that suggests Australian Aboriginal and Torres Strait Islander social work students and graduates continue to be impacted by dynamics of racism. The notion that racism remains a feature of social work practice is disturbing as Indigenous peoples are the most disadvantaged group in Australia on almost all social dimensions, and they are over-represented as recipients of social work services (Walter, Taylor, \& Habibis, 2011).

Recent efforts made by social work educators to be inclusive of Indigenous peoples, their history and ways of working are consistent with calls for the profession to find respectful ways of helping rather than continue to perpetuate deficit models of western intervention that have dominated past social work education and practice (see for example Green and Baldry, 2008; Yellow Bird, 2008). Responding to those calls for change, the Australian Association of Social Workers (AASW) has developed a Reconciliation Action Plan (2013), new Professional Standards (2013), a revised Code of Ethics (2010), and published special editions of the professional journal Australian Social Work to highlight issues of concern and to contribute to the development of inclusive social work practice and education with and for Indigenous 
Australians (http://www.aasw.asn.au/). However, the experience of field education for Indigenous students requires further exploration.

Field education provides real world preparation and professional enculturation in a human service organisation under supervision from an experienced social work practitioner. There is minimal literature that discusses the needs of Aboriginal and Torres Strait Islander students participating in field education, and no apparent exploration of whether Australian social work field placements appropriately serve the needs of Indigenous students. In recognition of this gap, the authors undertook a research project that aimed to explore with Aboriginal and Torres Strait Islander students their experiences on placement, the challenges of field education and their ideas for change in social work education. A discussion of the outcomes and recommendations from this research is developed elsewhere (Zuchowski, Savage, Miles, \& Gair, 2013). This article reports on the experiences of racism reported by the participants of the research project, despite no specific questions probing for racism experiences.

\section{Literature Review}

Social work is a vexed topic for Australian Aboriginal and Torres Strait Islander peoples due to the profession’s complicity in “...racist, patronising and unjust practices” (Green \& Baldry, 2008, p. 389), and because social work’s stated commitment to social justice has not translated effectively into structural equality for Indigenous Australians. There is a lack of acknowledgement of the Indigenous Australian perspectives that can inform social work practice and education (Gair, 2007; Green \& Baldry, 2008) and a corresponding reliance on EuroWestern social work skills and knowledge throughout the profession despite evidence that these approaches are not necessarily compatible with the Australian context (Walter, Taylor, \& Habbis, 2012). A lack of understanding about Aboriginal culture can mean that social work practitioners and educators resist, deny and challenge Aboriginal voices (Bennett, 2013). As a result, social work education participates in the institutional exclusion of Indigenous people, as 
“... the dominant pedagogical approach, assessment paradigm, and research methods converge to disregard and devalue Indigenous perspectives” (Larkin, 2011, p.2).

\section{Indigenous students and field education}

The literature identifies social work field education as a critical learning experience where students develop skills and knowledge in an authentic practice environment (Barton, Bell, \& Bowles, 2005). Yet Maidment (2003) exposed incongruent experiences for students on placement highlighting that important learning usually co-exists with significant anxiety. One learning impediment for minority students on placement identified by Gladstein and Mailick (1986) occurred when organisations, eager to use students' cultural insight and/or language skills, only assigned the student clients from the same ethnic group as the student. This may suit the client or agency needs, but not necessarily the learning needs of the student. These researchers recommended the use of cultural role models and the development of specific, culturally sensitive support programs to meet students’ unique needs.

More recently, Clark et al. (2010) undertook a collaborative study comparing the experience of Aboriginal and non-Aboriginal students on field placement in Aboriginal agencies in Canada. The authors called for Elder involvement in the students' education, anti-oppressive supervision practices, Aboriginal faculty liaison and the introduction of cultural safety preparation seminars. In the Australian context, Bessarab (2012) stressed that cultural supervision is essential for Aboriginal and Torres Strait Islander students, and argued that "No matter how well meaning, as a white or non-Aboriginal supervisor, their 'cultural' knowledge will still be based on what they have learnt and experienced as a person who is not Aboriginal” (Bessarab, 2012, p. 83).

The supervisory relationship in field education is described as crucial but inherently fraught with power inequities. Maidment and Beddoe (2012) highlighted the lack of Indigenous approaches and cultural knowledge in social work supervision models for Indigenous students 
and graduates. Such models require non-Indigenous social workers to “...give up their power and position as ‘experts’ in relation to Indigenous people” (Green \& Baldrey, 2008, p. 398) and to participate in “a de-privileging of workers’ expert knowledge” (Walter et al., 2012, p.239).

\section{Conceptual Frameworks}

The contested notions of "whiteness" and “racism” provide a conceptual framework for understanding some of the experiences described in the literature and in this project. "Whiteness" in particular is a relevant concept prominent in recent literature and understood here as a lens useful in identifying non-Indigenous people’s conscious or unconscious privilege when engaging with others (Singleton \& Fiahlo, 2011 cited in Bessarab, 2012). In this context "white” is not only used as a pigmentation-based construct but also refers to the racialised social structure evident in Australia where the dominance of white culture is unquestioningly accepted and preserved, thereby upholding the invisible privileges associated with whiteness (Kowal, 2008; Moreton-Robinson 2000).

"Whiteness" cannot be understood uncritically and recent research has noted the complexities of the concept. For example, literature from the United States has highlighted how certain immigrant groups such as Irish and Jewish groups though initially excluded from white identity have gained sufficient status and wealth to be afforded the privileges associated with whiteness (Zhou, 2004). Despite the potential for this changing demographic to influence the construct and experience of privilege, Jiménez and Horowitz (2013) acknowledge that such transformation is absent as the power of the privilege associated with whiteness is aspired to rather than challenged.

The construct of "whiteness" used in this project highlights the premise that the life chances of white and non-white people are determined by structural advantages that privilege white races across the world (Bessarab, 2012). Applied specifically to social work field education, whiteness can mean 
...that in supervision a liberal -minded supervisor who believes they are racially aware and on top of racism can inadvertently also be colour blind; failing to recognise ... when their white privilege is operational and their racial bias is challenging and/ or denying an Aboriginal ... student’s experience. (Bessarab, 2012, p. 83)

The notion of racism is an important and related dimension when the experiences of the participants in this project are considered. Dominelli identified that "Racism is the belief in the inherent superiority of one race over all others and thereby the right to dominance” (1997, p.7 citing Lorde, 1984, p.115). To advance an anti-racist paradigm for social work, Dominelli advanced a model that included individual racism, encompassing negative personalised prejudgements; institutional racism, where organisational norms ignore culture and reproduce racist interpersonal dynamics; and cultural racism, where "superior" values endorse and support individual and institutional racism. Castles (1996) highlighted how racism emerged historically escalating over time in response to resistance.

Racism does not always seek to exclude or exterminate the other. It is equally common for racists to seek to inferiorise and exploit minorities... the racism of exclusion and extermination was applied if the colonised group stood in the way of the coloniser's economic aims. (p26)

In a similar analysis specific to social work, Bessarab \& Crawford (2012, p. 106) warn

If social work is to transform and work differently with Indigenous people, it will need to apply a critical lens to examine the role that racism and whiteness play in constructing barriers that ... keep Aboriginal people down and treated differently. 
Bennett (2013) has similarly concluded that an examination of whiteness and an understanding of race and racism is an essential component of finding effective and respectful ways of working with Aboriginal and Torres Strait Islander people.

Considering the Eurocentric development and application of social work practice and the prevalence of racism at many levels and in many forms in Australia, it is likely that nonIndigenous Australian social work educators and placement supervisors have absorbed colonist views and racist attitudes towards Indigenous Australians (Green \& Baldry 2008). Recent research by Shahid, Durey, Bessarab, Aoun, and Thompson (2013) highlights the impact of this absorption on relationships and communication between non-Indigenous health practitioners and Aboriginal cancer patients.

[Cancer service providers] stereotyped Aboriginal patients and associated their non-assertiveness with cultural differences, lack of education and understanding. Most of them failed to reflect back on their own short-comings in the crosscultural communication process... Often providers seemed blind to the way that delivery of cancer care is inherently racialised. (9)

Consequently it could be inferred that colonialist attitudes potentially impact on educators' expectations of Aboriginal and Torres Strait Islander students', and on the appreciation of the unique learning needs of these students. Social work placements may thus become contested spaces where Aboriginal students feel unable to safely explore culturally relevant practice models and ethical dilemmas (Bessarab, 2012).

As mentioned earlier this research project investigated the experiences of Aboriginal and Torres Strait Islander students in social work field education. The literature presented above highlights that racism and white cultural dominance could adversely affect Indigenous 
students' experiences in social work education. This article examines this possibility using “whiteness” and “racism” as relevant critical frameworks to enhance understanding.

\section{Method}

This project was undertaken by a team of Indigenous and non-Indigenous researchers committed to processes of collaborative research. Our understanding of "collaborative research” reflected principles of respectful engagement with Aboriginal and Torres Strait Islander peoples and a commitment to participatory research that brought tangible benefits to the research participants (Bennett, Zubrzycki, \& Bacon, 2011). Implicit in the processes of collaborative research is an understanding of the social and historical reality of Aboriginal and Torres Strait Islander people and the application of cultural knowledge, values and priorities (Lynn et al., 1998).

In practice, the commitment to these principles was evidenced in the research team's discussions and reflections. Every stage of the research process was scrutinised to identify how Indigenous knowledge could inform the practicalities of the research process. Additionally the ethics approval process through the University Human Ethics Committee required the research team to articulate how the values and ethics specified in the NHMRC Guidelines for Ethical Conduct in Aboriginal and Torres Strait Islander Health Research (2003) were integrated as a framework for the participant recruitment strategies and research methods outlined in this paper.

\section{Research Aims}

This exploratory project was supported by an AASW research grant in recognition of the absence of literature and knowledge in the area of inquiry. We wanted to explore with Aboriginal and Torres Strait Islander students and graduates, their perceptions and experiences of social work field education. With this goal at the forefront we had three core aims:

- To explore the experience of Aboriginal and Torres Strait Islander social work students in field education placements; 
- To identify gaps, barriers and practices that inhibited positive placement experiences;

- To identify strategies and resources that could be used to support Aboriginal and Torres Strait social work students in field education placements.

To achieve these aims, we sought to recruit Aboriginal and Torres Strait Islander social work students or graduates who had completed at least one social work field education experience. Current and past students who met these criteria were identified from the Departmental data base and sent generic letters explaining the research and inviting participation. The letters were sent from the field education unit and invited potential participants to contact one of the Indigenous research team members for further discussion. The team was particularly alert to the power differential between students and staff and the opportunities to influence future departmental practices was an important issue discussed with potential participants. After discussions with Indigenous members of the research team, participants were asked to sign informed consent forms which highlighted the voluntary nature of research participation and the participants' right to withdraw at any time without consequence.

\section{Participants}

Eleven participants responded to the invitation to participate in this study, ten Bachelor of Social Work students or graduates and one Bachelor of Community Work graduate, who was included because of her highly relevant experience. Ten of the project participants were women broadly reflecting the gender distribution of social work students at James Cook University. Participants were aged between 29 and 55 years of age. Two participants were current students having completed their first field education experience within the last two years. The other nine participants were graduates, the majority of whom had graduated within the last five years. Where participants drew on field placement experiences from more than five years ago, they provided examples of similar experiences drawn from their current working lives as social workers. It was clear from the interview transcripts that participants considered their experiences 
holistically, drawing on aspects of their contemporary professional work as well as placement experiences.

\section{Data Collection}

Data was collected through semi structured interviews with individual participants and through a focus group. Primarily, interviews were conducted by Aboriginal members of the team to promote a sense of cultural safety for participants. While general prompts guided the interview, participants were encouraged to share their experiences as they chose reflecting the claim by Clark et al. (2010, p. 12) that "oral storytelling and narrative analysis are best situated to listen to the stories and experiences of Aboriginal students” and this research affirmed that process.

All participants were invited to join in a focus group discussion conducted at a local venue with refreshments provided. While only three participants were available to join the group due to distance and prior commitments, the discussion was robust. The focus group was facilitated by an Aboriginal member of the research team. A de-identified summary of the issues raised by participants during the interviews was shared with group for further debate, with the Aboriginal facilitator assisting the group by “connecting events, actions and experiences” (Bennett, 2013, p. 3). In the focus group participants supported each other to unpack the nature of their field education placements through further reflection on the events described during individual interviews, highlighting previously unexplored aspects of their experience (Acocella, 2012). The collaborative processes that underpinned the focus group methods are core to culturally respectful practice in Aboriginal and Torres Strait Islander social work (Zubrzycki \& Crawford, 2012). New data resulted from these processes as the interaction between participants created a sense of safety and prompted an expansion of their stories. For example, data from the interviews suggested that supervisor preparation was inadequate. Focus group participants engaged in robust debate and made specific recommendations for identifying and developing 
cultural responsiveness in supervisors. These specific recommendations have now been included in preparatory field educator training at our university (Zuchowski et al., 2013).

\section{Data Analysis}

The process of drawing interpretations from the stories and ideas presented in interviews and the focus group was intertwined with an ongoing recognition of the presence of ourselves as researchers in the data and in our interpretations. Interviews were digitally recorded, transcribed verbatim and the written transcripts were read by the research team members together as a group, on multiple occasions. Each team member raised issues or participant comments and these were recorded firstly on a white board as an immediate shared resource and later transcribed and distributed to each team member for further collaborative exploration. The differing perspectives from each team member were drawn together over many group discussions. This process was guided by the Aboriginal members of the team who shared their interpretations of the language, thoughts and feelings apparent during the interviews, and their understanding of the participants’ intent, not immediately discernible in written transcripts or through non-Indigenous eyes. Where non-Indigenous members of the research team highlighted certain frameworks as possibly influencing the perception of the event, the Aboriginal team members were able to confirm or challenge such interpretations through shared understandings of lived experiences (Frost et al., 2011). An illustration of this process is evident in the Aboriginal and Torres Strait Islander research team members' response to the non-Indigenous researchers' shock at the extent of racism described by participants. For the Aboriginal and Torres Strait Islander researchers such events were a fact of everyday life not able to be objectified as a particular "research finding" and they directed the process of analysis and data presentation to focus on other themes of the research first. This prompted a discussion on how "whiteness" and the privilege that accompanies that identity for some of the team members allowed them to "discover" these racist events as particular and specific to the field education context. 
The small number of respondents in this study limits the generalizability of the data and it is acknowledged that the experiences described in the remainder of this paper all occurred in North Queensland. However, when combined with ideas discussed in the literature and especially acknowledging recent publications from Indigenous social workers, Bennett (2013) and Besserab (Shahid et al., 2013), the experiences described can be viewed as having a broader relevance than just North Queensland.

\section{Findings}

As is discussed in an earlier section of this paper, the research project focused on the overall experiences of Aboriginal and Torres Strait Islander students in field education. An examination of those findings revealed that Aboriginal and Torres Strait Islander students experienced significant racism in their placements and later in their professional practice and workplaces. The following discussions focus on this particular aspect. Students experienced the hurt of personalised racist language and behaviour, and the frustrating obstruction of institutional racism. Participants described the impact of these experiences and their responses, and identified what strategies facilitated their progression through a difficult placement. These experiences are presented in participants' own words, differentiated by pseudonyms. While more general findings of the study have been reported elsewhere (Zuchowski et al., 2013), here we specifically seek to spotlight evidence of racism.

\section{Personal and Organisational Experiences of Racism}

\section{Alone and Isolated}

The participants in this study often found themselves to be the only Aboriginal person in the organisation and described this as a difficult and intimidating experience. For example Tara commented "It was quite daunting ... I was the only Indigenous person in that organisation”.This initial dismay expressed by a number of participants became a 
compounded sense of isolation and exclusion when the organisation demonstrated no understanding of Aboriginal and/or Torres Strait Islander culture. Kimberley commented “Y’know it’s manned by a lot of white middle class people. Women who really don't have a concept of Aboriginal issues, Aboriginal perspectives ... I found that to be ... really quite racist”.

\section{Inappropriate Assumptions}

As the comments above indicate, a lack of cultural awareness and understanding within agencies created feelings of isolation and frustration for students but of more concern was the inappropriate and racist assumptions made by non-Indigenous staff in the organisation. While sometimes unintentional, these assumptions have the effect of communicating the inferior status of Aboriginal and Torres Strait Islander people to the student or worker maintaining the status of white workers and privileging white ways.

These assumptions included ideas about what "true” Indigenous people look like. For example, Jane reported being told she was “not black enough” and Kimberley described the following incident:

A white woman came up to me, and said ... "you have to go to this meeting because there's a couple of women coming” ... She said "I know one of them is Aboriginal because she looks like it, but I'm not sure if the other one is. ... she just doesn't look Aboriginal”. And I said, "well what are we supposed to look like”?

An examination of these comments through a "whiteness" lens reminds us that it is white people who have the power and the privilege to determine how "Indigenous" looks. Using a critical "whiteness" lens, this question becomes less about "assigning racial allegiances" and more about the “mechanisms of racialization” (Gunew, 2007, p. 43). It seems that non- 
Indigenous people, without critical reflection, claim authority to question or prescribe who is assigned the category of "Indigenous” and "Other”.

Similarly, participants identified other behaviours that minimised the individuality of Indigenous people, homogenising Aboriginal and Torres Strait Islander people in a way that denied respect for differences within cultures.

One thing I came up against was ... they just assumed, that because of the colour of our skin that we were all the same. In other words, if a person was Aboriginal, because I speak Torres Strait Creole, they thought that I could actually talk to that Aboriginal person. And I couldn’t, and I explained ... “I can yarn to this person but I can’t speak in their language...” And the comment was, “oh, it’s all the same”. (Denise)

Respondents shared experiences that indicated others in their placement organisation were incredulous that Indigenous people were in professional positions or positions of authority. For example, Leanne commented “I went into the [government department]- you weren’t recognised as a social worker there, because Indigenous people weren't supposed to have education.” Reminiscent of the research by Gladstein and Mailick (1986), some participants reported only certain tasks were deemed suitable for Indigenous students and workers cultural activities or those tasks that had an obvious connection to Indigenous clients or culture.

Because of me being Indigenous, they put me in to do cultural stuff too. ... and I've even said to them " I'm a qualified social worker. I did the hard yards; I did the practice, the actual placements. ” And they get a shock. (Denise) 
These experiences reflect Castles' (1996) argument that effective racist processes are as much intended to inferiorise and exploit colonised people as they are to exterminate them. Juliet powerfully describes the impact of these processes: “They like to use us, but they don't think you can do the job, ....And that's been a fear of my life, ... That you're not worthy, I felt unworthy, ...-that I couldn’t do the job that they could do”.

\section{Abuse and Derision}

A number of the participants in this study graciously described the above assumptions as hurtful but perhaps resulting from a lack of understanding. Equally, they identified and named comments and behaviours that were more explicitly racist and abusive. David's experience of being publicly abused provides a graphic example:

I was on rotation at the acute unit and there was a patient down there, a Torres Strait boy, and I knew his family... So I think this is when my cultural background first came up as a student, cos ... there was a few nurses and they asked me to talk to this client. ... he was around my age so I thought I'd be able to talk to him about what's going on ... My supervisor, ... said to me, in front of all them other staff, "I fuckin heard that you were effin doing this over there. You should not be doing that.” She was pointing at me ... “... That’s not your friggin role.”

A related but different point in the literature on this topic, particularly from Gladstein and Mailick (1986), highlights how abuse does not need to be explicitly directed at the student to be experienced as a racist assault. When Aboriginal and Torres Strait Islander people are treated with disrespect or when Aboriginal and Torres Strait Islander people are depicted as dangerous or undesirable, students are equally impacted. For example, one participant described an incident where Aboriginal communities were depicted as violent, sexually 
depraved "shit - holes". This racial stereotype left the student feeling shocked and offended. Other participants suffered allegations that were the product of negative stereotyping and prejudicial attitudes such as Juliet’s experience when a neighbour told her “oh well, I know you have all your rates and your house paid for by the government”.

\section{Lived experiences of disadvantage}

Some participants reported a lack of understanding from their field educator, and from the placement organisation more widely, about the personal issues that impacted on their lives. This was despite an acknowledgement, at least at an intellectual level, of the hardships confronting Aboriginal and Torres Strait Islander people in Australian society. This intellectual understanding often was not transferred into empathy for the student as is exemplified in Jane’s account: “At the time I was basically homeless, I had to quickly leave the residence that I was in. The supervisor ...had a go at me, because I wasn’t prepared for my first meeting for her.”

The apparent inability of placement supervisors to empathically link the history of Aboriginal and Torres Strait Islander people with the lived experiences of the Indigenous students in their agency is graphically described by one student who was involved in the removal of children from an Aboriginal family without warning or support.

I didn’t know I was going to take children off their parents, just barge in take them, no empathy, no nothing, ay, they were taking children, the parents were crying ... I come out crying, too, you know. (Juliet)

The lack of recognition of the students' lived experience resonates with Bennett's (2013) recent research which emphasises the trauma and loss suffered by Aboriginal and Torres 
Strait Islander social workers as a consequence of the same devastating health and social issues experienced by Indigenous community in general.

Non Indigenous people as “experts”

The literature that informs the context for this research highlighted the calls for nonIndigenous social workers to relinquish their self-proclaimed expertise about Indigenous people, and instead to learn from the knowledge and wisdom of Aboriginal and Torres Strait Islander peoples - including students. This is not to suggest that students believed they had nothing to learn on placement but instead highlights the difficulty many non-Indigenous professionals have in relinquishing the power of "knower" especially in deference to Indigenous students. Denise explained "I just found that some staff think that they were an authority on Indigenous stuff. ... because they've worked in that community..., but it does not make you an Indigenous person, it never will”.

Some students were denied opportunities to use their cultural expertise as this unique knowledge challenged the power of the field educator role and was resisted strongly by some supervisors. David's experience, further described here after he spoke with a client in "language" that he and the client shared, attests to this.

She said, "Look, you're not a qualified interpreter... and you shouldn't be doing that, you're a student, you're in a learning role.” And I said, "I am in a learning role but I do know how to speak my language.”

\section{Reactions to racism}

The participants in this project described two consistent responses to these racist experiences; to ignore it or to challenge it. Both responses had costs associated and 
predominantly the participants did not consider either response impacted significantly on the situation.

Ignore and move on

Some participants talk about ignoring the comments and behaviours; to "get on" with things and just "get through it": "I decided to just let it go because there was only a few weeks left to finish the placement, but I felt like ...the whole purpose of it was ...like a punishment”(Lucy). Particularly poignant in these responses is the sense that such behaviours are not uncommon or rare and are experiences Aboriginal and Torres Strait Islander people suffer every day: "Its constant stuff, but what do you do? You ignore it and just keep going, you know, and I found by keeping on going, and dusting your feet, you achieve a lot, you know” (Juliet).

\section{Challenge ... but it costs}

Some participants reported that they had challenged the behaviours they witnessed. These participants described how they were not supported by their supervisors. Instead staff and supervisors attempted to justify the behaviour often perpetuating further racism, as is described by Kimberley:

I said “you cannot allow things like that to go on” but she supported this other woman, ... and she said things to me like, “I’ve known this woman a long time and she’s had Aboriginal friends for as long as I’ve known her." And y'know "she’s not a racist, because she has Aboriginal friends."

The cost of speaking out was not lost on these participants and many recognised the futility of attempting to change a system based on, and maintained by, white privilege as illustrated by this comment: "If you name racism, then you are the problem..... When I get 
up and I speak out against a non-Indigenous student, I'm labelled as an aggressive person, or a bully” (Jody).

\section{Strategies to facilitate change}

Participants were not completely without support or coping strategies. Consistently they identified that other Indigenous students and Indigenous workers helped them cope with the dilemmas and problems they encountered. "Having a mate” was essential to the success of many of the placements. Formalising this support from other Aboriginal and Torres Strait Islander people was a key strategy for change recommended by participants. The use of a cultural mentor was the favoured option among these students and graduates: "If they don't have the quals... and more than likely, ...you're not going to get an Aboriginal person with the right qualifications, but ...have a mentor there with the supervisor, so if there is any issue... that person is there" (Kimberly).

Another strategy was the development of thorough placement preparation for Indigenous students prior to the commencement of placement. The current generic student preparation was considered insufficient to deal with the multiple issues that impact on placements with Aboriginal and Torres Strait Islander students. Tara suggested a more specific, focussed approach; “Take them out, introduction to the workplace... their policy and stuff, how they can be supported... how they work culturally in that organisation and stuff.”

Participants also proposed that the formal processes of the university be used to assess the cultural suitability of field educators. Just being willing was not good enough in their view, and participants expected supervisors to have at least some cultural understanding and some preparedness to examine their own cultural biases: "I believe that they should be screened appropriately for what their cultural competence is, what their cultural supervision expertise is, and what their cultural knowledge is and just their general outlook on Aboriginal and 
Torres Strait Islander culture" (David). These suggestions were made with the acknowledgement that even the best of preparation may not protect students from some of the experiences reported in this research.

\section{Discussion}

The findings described above identify that Aboriginal and Torres Strait Islander social work students often felt culturally unsafe and experienced significant racism in their field placements. Further, the racism they experienced on field placement mirrored the life-long experiences of the participants as Aboriginal and Torres Strait Islander people in Australia. Their social work placement experience was no different to everyday life, much of which is impacted by racism, and a lack of recognition and valuing of their cultural identity. Participants used various strategies to survive, however, the concept of “dusting oneself off” articulated by one participant resonated with other participants in the focus group meeting (Zuchowski et al., 2013).

As noted earlier, Dominelli $(1997,2008)$ identified an inter-connecting model that included personal, institutional and cultural racism, and this study provides evidence that all these forms of racism were experienced as normal and part of day-to day existence by participants (Atkinson, 2002). The use of a "whiteness" perspective in acknowledging these experiences prescribes the responsibilities of non-Indigenous people in rendering such racism more visible. In fact, Dominelli specifically highlights the academy's responsibility for bringing about change in these circumstances. She writes that "White educators can promote movement on this front by collectively refusing to continue to be misused as 'race experts'... (and by) redefining the problem ... as institutional racism” (Dominelli, 1997, p.65). It is evident from these findings that despite efforts of non-Indigenous social work staff, they are not bringing about change in this situation; they are not always providing safe placements, and racism remains an everyday experience even in placements. Non-Indigenous social work educators must join with others in 
the human services field in relinquishing control of the "expert educator" space, enabling Indigenous staff to enter and support Indigenous students' learning experiences. Bessarab (2012, p. 83) elaborates on this strategy:

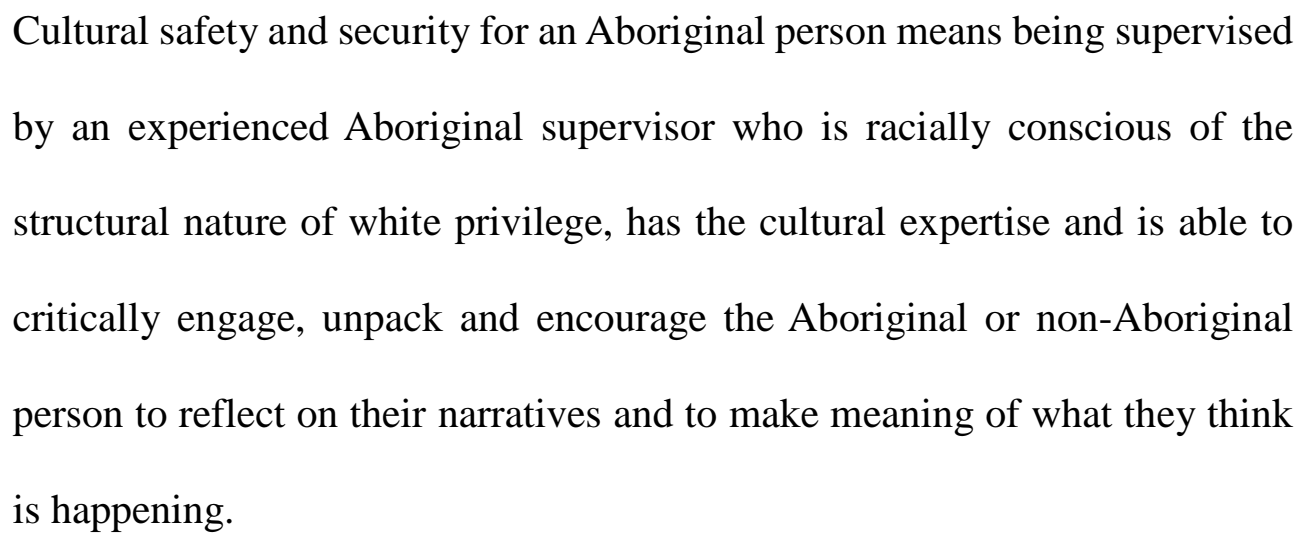

These suggestions echo participants' recommendations for the inclusion of cultural mentors and a focus on cultural safety in field education programs. The urgent employment of Indigenous staff in leadership and cultural support roles is crucial in supporting Indigenous students to have positive, authentic learning experiences in order to facilitate their development as Indigenous social work practitioners.

Other findings point to the need for educators to recognise Indigenous students' lived experiences. Demonstrating this awareness in a meaningful way requires a dual response from university and field educators. The need for additional practical support in the face of material disadvantage is required and an embracing attitude must be fostered where students are recognised as both learners and holders of knowledge. Training that prepares educators for this complex but necessary response is an important recommendation for change.

\section{Conclusion}

The findings from this study revealed that many forms of racism experienced in social work placements are no different to Indigenous students' everyday life experiences. Strategies paramount for Indigenous social work students' cultural safety include: placement preparation 
(including agency staff preparation); cultural support which includes elders and mentors to buffer experiences of racism; Aboriginal and Torres Strait Islander academic staff; and enduring antiracism strategies to counter personal, organisational and cultural racism in the university and in partner organisations. We recommend and seek to drive the implementation of these strategies to continue to confront racism in our profession, inform our professional guidelines, transform practices in our own university, and support partner placement organisations to do the same. 


\section{Acknowledgements}

This project was funded through an AASW practitioner research grant. We would like to acknowledge the participants' generous sharing of their stories. Further we acknowledge the contributions of Patricia Johnson, an Indigenous Student Support Officer; Lisa Curtis, an Indigenous social work student on field placement with this project; and Lyn Munns, an Indigenous Student Support Officer, who brought important insights to our analysis. 


\section{REFERENCES}

Acocella, I. (2012). The focus groups in social research; advantages and disadvantages. Quality \& Quantity, 46(4), 1125-1136.

Atkinson, J. (2002). Trauma trails. Recreating Song Lines. The transgenerational effects of trauma in Indigenous Australia. North Melbourne: Spinifex Press.

Australian Association of Social Workers. (2013). Practice Standards. Retrieved from http://www.aasw.asn.au/document/item/4551

Barton, H., Bell, K., \& Bowles, W. (2005). Help or hindrance? Outcomes of social work student placements. Australian Social Work, 58, 301-312. doi: 10.1111/j.14470748.2005.00222.x

Bennett, B., Zubrzycki, J., \& Bacon, V. (2011). What do we know? The experiences of social workers working alongside Aboriginal people. Australian Social Work, 64, 20-37. doi:10.1080/0312407X.2010.511677

Bennett, B. (2013) “Stop deploying your white privilege on me!” Aboriginal and Torres Strait Islander engagement with the Australian Association of Social Workers. Australian Social Work. Published online November 2013. doi:10.1080/0312407X.2013.840325

Bessarab, D. (2012). The supervisory yarn: embedding Indigenous epistemology in supervision. In B. Bennett, S. Green, S. Gilbert \& D. Bessarab (Eds.), Our Voices. Aboriginal and Torres Strait Islander Social Work (pp. 73- 92). South Yarra, Melbourne: Palgrave Macmillan.

Bessarab, D., \& Crawford, F. (2012). Trauma, grief and loss: the vulnerability of Aboriginal families in the child protection system. In B. Bennett, S. Green, S. Gilbert \& D 
Bessarab. (Eds.), Our Voices. Aboriginal and Torres Strait Islander Social Work (pp. 93-113). South Yarra, Melbourne: Palgrave Macmillan.

Castles, S. (1996) The racisms of globalisations. In E. Vasta and S. Castles (Eds.), The teeth are smiling. The persistence of racism in multicultural Australia (pp. 17-45). St Leonards, NSW: Allen \& Unwin.

Clark, N., Drolet, J., Mathews, N., Walton, P., Tamburro, P., Derrick, J., ... \& Arnouse, M. (2010). Deconlonizing field education:"Melq'ilwiye" coming together: An exploratory study in the interior of British Columbia. Critical Social Work, 11(1). Retrieved from http://www1.uwindsor.ca/criticalsocialwork/

Dominelli, L. (1989). An uncaring profession: An examination of racism in social work. Journal of Ethnic and Migration Studies 15, 391-403. DOI:10.1080/1369183X.1989.9976127

Dominelli, L. (1997). Anti-racist Social Work. (2 ${ }^{\text {nd }}$ ed.). London: Macmillan Press.

Dominelli, L. (2008). Anti-racist Social Work. (3 ${ }^{\text {rd }}$ ed.). London: Palgrave Macmillan

Frost, N.A., Holt, A., Shinebourne, P., Esin, C., Nolas, S., Mehdiadeh, L., \& Brooks-Gordon, B. (2011). Collective findings, individual interpretations: An illustration of a pluralistic approach to qualitative data analysis. Qualitative Research in Psychology, 8(1), 93-113.

Gair, S. (2007). Developing Indigenous-inclusive curriculum in tertiary education. Feeling my way as a non-Indigenous educator. Australian Journal of Indigenous Education, 36, 49-55.

Gladstein, M., \& Mailick, M. (1986). An affirmative approach to ethnic diversity in field work. Journal of Social Work Education, Winter (1), 41-49. 
Green, S., \& Baldry, E. (2008). Building Indigenous Australian social work. Australian Social Work, 61, 389-402. doi: 10.1080/03124070802430718

Gunew, S. (2007). Rethinking Whiteness: Introduction. Feminist Theory, 8, 41-47. doi: $10.1177 / 1464700107078138$

Jiménez, T \& Horowitz, A. (2013) When white is just alight: How immigrants redefine achievement and reconfigure the ethnoracial hierarchy. American Sociological Review 78, 849-87. doi:110.1177/0003122413497012

Kowal, E. (2008). The politics of the gap: Indigenous Australians, liberal multiculturalism and the end of the self-determination era. American Anthropologist, 110(3), 338-348. DOI: 10.1111/j.1548-1433.2008.00043.x

Larkin, S. (2011). Indigenous Perspectives: Enriching Scholarship and Practice. Australian Social Work, 64 , 2-5. doi: 10.1080/0312407X.2011.542610

Lynn, R., Thorpe, R., Miles, D., Cutts, C., Butcher, A., \& Ford, L. (1998). 'Murri Way!'Aborigines and Torres Strait Islanders reconstruct social welfare practice. Townsville: Centre for Social and Welfare Research, JCU.

Maidment, J. (2003). Problems experienced by students on field placement: using research findings to inform curriculum design and content. Australian Social Work, 56, 50-60. doi: 10.1046/j.0312-407X.2003.00049.X

Maidment, J. \& Beddoe, L. (2012). Is social work supervision in 'Good Heart'? A critical commentary, Australian Social Work, 65, 163-170. doi: 10.1080/0312407X.2012.680426 
McMahon, T. (1990). Social Work and Aborigines. Australian Social Work. 43(3),11-14. doi: $10.1080 / 03124079008550087$

Moreton-Robinson, A. (2000). Talkin' up to the white woman. Indigenous women and feminism. St. Lucia, Brisbane: University of Queensland Press.

National Health and Medical Research Council. (2003) Values and Ethics: Guidelines for Ethical Conduct of Aboriignal and Torres Strait Islander Health Research. Retrieved from https://www.nhmrc.gov.au/_files_nhmrc/publications/attachments/e52.pdf

Shahid, S., Durey, A., Bessarab, D., Aoun, S. \& Thompson, S. (2013) Identifying barriers and improving communication between cancer service providers and Aboriginal patients and their families: the perspective of service providers. BMC Health Services Research, 13(460) doi:10.1186/1472-6963-13-460

Walter, M., Talylor, S., \& Habibis, D. (2012). Australian social work is white. In B. Bennett, S. Green, S. Gilbert \& D. Bessarab (Eds.), Our Voices. Aboriginal and Torres Strait Islander Social Work, (pp. 230-247). South Yarra, Melbourne: Palgrave MacMillan.

Yellow Bird, M. (2008). Terms of endearment: A brief dictionary for decolonising social work with Indigenous people. In M. Gray. J. Coates, and M. Yellow Bird (Eds.), Indigenous social work around the world, (pp. 275-291). Hampshire, Great Britain: Ashgate.

Zhou, M. (2004). Are Asian Americans becoming “White”? Contexts. 3,29-37. doi:10.1525/ctx.2004.3.1.29

Zubrzycki, J. \& Crawford, F. (2012) Collaboration and relationship building in Aboriginal and Torres Strait Islander social work. In B. Bennett, S. Green, S. Gilbert \& D. Bessarab (Eds.), Our Voices. Aboriginal and Torres Strait Islander Social Work, (pp. 181-205). South Yarra, Melbourne: Palgrave MacMillan. 
Zuchowski,I., Savage, D., Miles, D., \& Gair, S. (2013). Decolonising Field EducationChallenging Australian Social Work Praxis. Advances in Social Work and Welfare Education, 15 (1), 47-62. 